\title{
Autoimmune liver disease: overlap and outliers
}

\author{
Mary K Washington \\ Department of Pathology, Vanderbilt University Medical Center, Nashville, TN, USA
}

\begin{abstract}
The three main categories of autoimmune liver disease are autoimmune hepatitis (AIH), primary biliary cirrhosis (PBC), and primary sclerosing cholangitis (PSC); all are well-defined entities with diagnosis based upon a constellation of clinical, serologic, and liver pathology findings. Although these diseases are considered autoimmune in nature, the etiology and possible environmental triggers of each remain obscure. The characteristic morphologic patterns of injury are a chronic hepatitis pattern of injury with prominent plasma cells in AlH, destruction of small intrahepatic bile ducts and canals of Hering in PBC, and periductal fibrosis and inflammation involving larger bile ducts with variable small duct damage in PSC. Serological findings include the presence of antimitochondrial antibodies in PBC, antinuclear, anti-smooth muscle, and anti-LKM antibodies in AIH, and PANCA in PSC. Although most cases of autoimmune liver disease fit readily into one of these three categories, overlap syndromes (primarily of AIH with PBC or PSC) may comprise up to $10 \%$ of cases, and variant syndromes such as antimitochondrial antibody-negative PBC also occur. Sequential syndromes with transition from one form of autoimmune liver disease to another are rare.

Modern Pathology (2007) 20, S15-S30. doi:10.1038/modpathol.3800684
\end{abstract}

Keywords: autoimmune liver disease; autoimmune hepatitis; primary biliary cirrhosis; primary sclerosing cholangitis; overlap syndrome

The three major categories of autoimmune liver disease are autoimmune hepatitis (AIH), primary biliary cirrhosis (PBC), and primary sclerosing cholangitis (PSC). Although each of these entities has well-defined clinical, morphologic, and serologic profiles (Table 1), variant and atypical forms are not uncommon, and overlap syndromes, primarily between $\mathrm{AIH}$ and $\mathrm{PBC}$, and $\mathrm{AIH}$ and PSC are increasingly recognized.

\section{Autoimmune hepatitis}

\section{Definition}

Recognized as a clinical entity for over 50 years, $\mathrm{AIH}$ is generally characterized as an unresolving hepatitis usually associated with hypergammaglobulinemia and tissue-directed autoantibodies and responding in most cases to immunosuppressive therapy. The pathogenesis appears to be aberrant autoreactivity in genetically susceptible individuals.

Correspondence: Dr MK Washington, MD, PhD, Department of Pathology, Vanderbilt University Medical Center, C-3321 Medical Center North, Nashville, TN 37232, USA.

E-mail: kay.washington@vanderbilt.edu

Received 14 July 2006; accepted 26 July 2006
Epidemiology and Demographic Features

The worldwide prevalence of AIH is unknown; most reported cases are in patients of European Caucasian or Japanese extraction. In North American populations, the prevalence is estimated as $\sim 1$ per 100000 population. ${ }^{1}$ In Western Europe and North America, where viral hepatitis prevalence rates are relatively low, AIH accounts for roughly $20 \%$ of chronic hepatitis in the white populations.

In patients of European descent, AIH is associated with the HLA A1-B8-DR3 haplotype and particularly with DR3. In Japan, it appears to be primarily associated with the DR4 haplotype; ${ }^{2}$ this form of the disease occurs in elderly patients who exhibit mild necroinflammatory activity and a good response to immunosuppressive therapy.

\section{Clinical Features}

$\mathrm{AIH}$, like most autoimmune disorders, is more common in female patients, with a male:female ratio of roughly 1:4. It can present at any age, but younger patients appear to have a more severe form of the disease. Presentation varies widely, ranging from asymptomatic elevations of serum liver enzymes, to massive hepatic necrosis resulting in fulminant hepatic failure. Most patients present 
Table 1 Autoimmune liver diseases: clinicopathologic features (adapted from Beuers ${ }^{73}$ )

\begin{tabular}{|c|c|c|c|c|}
\hline & $A I H$ & $P B C$ & $P S C$ & $A I C^{\mathrm{a}}$ \\
\hline Female:male & $4: 1$ & $9: 1$ & $1: 2$ & $9: 1$ \\
\hline $\begin{array}{l}\text { Predominant liver test } \\
\text { elevation }\end{array}$ & AST, ALT & Alk phos, $\gamma$-GT & Alk phos, $\gamma$-GT & Alk phos, $\gamma$-GT \\
\hline Serum Ig elevation & $\operatorname{IgG}$ & $\operatorname{IgM}$ & IgG, IgM & $\operatorname{IgM}$ \\
\hline Autoantibodies & $\begin{array}{l}\text { ANA, ASMA, LKM1, SLA/P, } \\
\text { pANCA }\end{array}$ & AMA, AMA-M2, gp210 & p-ANCA & ANA, ASMA \\
\hline HLA association & $\mathrm{A} 3, \mathrm{~B} 8, \mathrm{DR} 3, \mathrm{DR} 4$ & DR8 (weak association) & DR52 & B8, DR3, DR4 \\
\hline Histology & $\begin{array}{l}\text { Interface and lobular } \\
\text { hepatitis; prominent plasma } \\
\text { cells }\end{array}$ & Florid bile duct lesion & $\begin{array}{l}\text { Fibrosis and obliteration } \\
\text { of large bile ducts; } \\
\text { ductopenia }\end{array}$ & Florid bile duct lesion \\
\hline Diagnosis & $\begin{array}{l}\text { AIH score }>15 \text { for diagnosis } \\
\text { of definite AIH }\end{array}$ & $\begin{array}{l}\text { AMA, cholestatic serum } \\
\text { enzyme pattern, } \\
\text { compatible histology }\end{array}$ & $\begin{array}{l}\text { Biliary strictures and } \\
\text { dilatation on } \\
\text { cholangiography; } \\
\text { cholestatic serum enzyme } \\
\text { pattern, IBD, p-ANCA }\end{array}$ & $\begin{array}{l}\text { Cholestatic serum enzyme } \\
\text { pattern, AMA neg, ANA } \\
\text { or ASMA positive; } \\
\text { histology c/w PBC }\end{array}$ \\
\hline $\begin{array}{l}\text { First-line medical } \\
\text { therapy }\end{array}$ & $\begin{array}{l}\text { Immunosuppression } \\
\text { (corticosteroids+ } \\
\text { azathioprine) }\end{array}$ & $\begin{array}{l}\text { Ursodeoxycholic acid } \\
\text { (UDCA) }\end{array}$ & UDCA & UDCA \\
\hline
\end{tabular}

${ }^{\mathrm{a}}$ Autoimmune cholangitis.

with a prodrome phase characterized by a flulike illness and lethargy; indeed, the latter may be the only symptom. About half of the patients with a prodromal phase will be icteric at some point. About one-third of patients are cirrhotic at presentation, confirming the impression that AIH often has a prolonged subclinical phase. Approximately $30 \%$ of patients, usually younger patients, will have an acute presentation mimicking acute viral hepatitis. The response to therapy and prevalence of cirrhosis at presentation are the same as in patients who present with more insidious onset. Roughly $20 \%$ of patients will be asymptomatic, with elevated transaminases identified on screening examination or during evaluation for amenorrhea, thyroid disease, arthralgia, or diabetes mellitus. Frequency of cirrhosis in this group at presentation is similar to that for symptomatic patients. In children, acute presentation is common, and the patients are more likely to be cirrhotic $(60-80 \%)^{3}$

About $50 \%$ of patients with AIH will have concurrent autoimmune disorders, most commonly thyroid disease or rheumatoid arthritis. The presence of ulcerative colitis, however, should raise questions about the diagnosis of $\mathrm{AIH}$; such patients are more likely to have PSC.

\section{Diagnosis}

AIH is diagnosed by consideration of the combination of clinical and laboratory features with exclusion of other causes of liver disease such as viral hepatitis, Wilson's disease, alpha-1-antitrypsin deficiency, PBC, PSC, alcohol abuse, and drug reaction. Diagnosis is straightforward in 50\% and is aided by serum studies and the scoring system developed by the International Autoimmune Hepatitis Working Group., ${ }^{4,5}$

\section{Serum studies}

Characteristic biochemical abnormalities include elevated transaminase levels, often accompanied by hyperbilirubinemia, hypergammaglobulinemia with a disproportionate increase in serum IgG, and normal or only slightly elevated alkaline phosphatase. Aminotransferases and bilirubin levels may vary widely, however, and may even normalize spontaneously for a period of time, and thus no threshold level for aminotransferases for diagnosis of AIH is specified. Bilirubin and transaminase levels do not reliably reflect disease severity. Total globulins may be in the normal range, and $\operatorname{IgM}$ levels are not as elevated as in PBC.

Seventy to eighty percent of patients with $\mathrm{AIH}$ have antinuclear antibody (ANA) or smooth muscle antibody (SMA) or both $(\geq 1: 40)$. Because the ANA react mainly with histones and DNA, the pattern is homogeneous, similar to that seen in lupus; other patterns also occur, with no apparent clinical significance. ${ }^{6}$ The autoantibody titer does not reliably reflect disease severity. The SMA reacts with several cytoskeletal components, including F-actin.

Three to four percent of overall patients (usually children) present with anti-liver kidney microsomal (LKM1) antibodies, without ANA or SMA. This serologic marker is more common in southern Europe but the true prevalence is not known. The antibody is directed against P450(CYP)2D6 and is associated with $D R B 1^{*} 0701$ allele. $^{3}$

Antibodies against the soluble liver antigen/liver pancreas antigen (SLA/LP) are found in 10-30\% with AIH; although testing for this autoantibody is not routine, it appears to have a global distribution. pANCA, while not specific, is present in $60-90 \% .^{3}$

\section{Histopathology}

Key histologic features of AIH are a chronic hepatitis pattern of injury, with portal and periportal lym- 
phoplasmacytic infiltrates (Figure 1) and interface hepatitis (Figure 2). Plasma cells (Figure 3) are often but not always prominent, and are sometimes seen singly and in clusters in the lobule. The severity of necroinflammatory activity is quite variable, ranging from mildly active hepatitis (Figure 4) to bridging necrosis to massive hepatic necrosis. Hepatocyte regeneration may be prominent, with regenerating rosette-like structures. Ballooning degeneration, spotty hepatocyte necrosis, and apoptotic bodies are common but not specific. Syncytial multinucleated hepatocyte giant cells are seen in some cases and many cases of the so-called giant cell hepatitis probably represent a variant of AIH. ${ }^{7}$ As the disease progresses, periportal fibrosis with formation of portal-portal and portal-central bridges and nodular regeneration results in cirrhosis, often with severe necroinflammatory activity. In most cases, the necroinflammatory process responds promptly

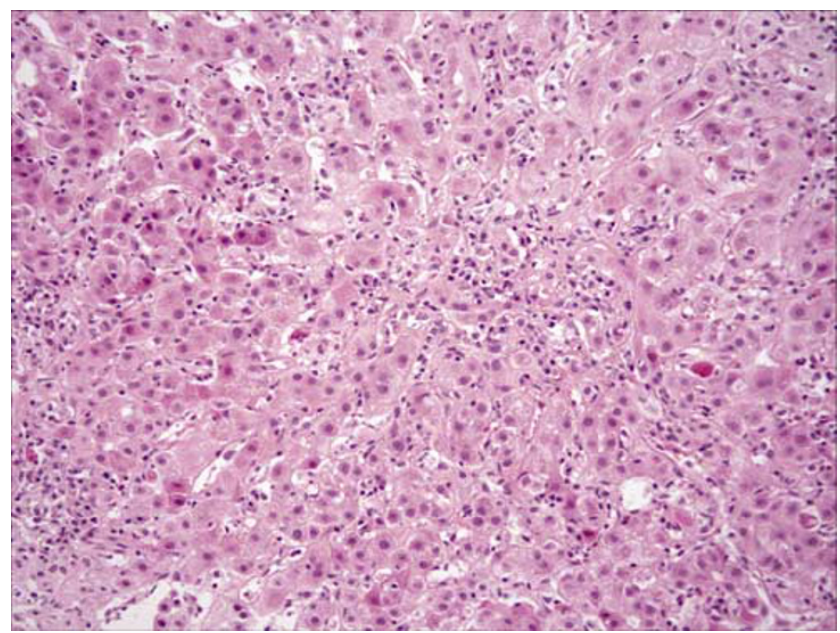

Figure $1 \mathrm{AIH}$. Lobular necroinflammatory activity is often prominent.

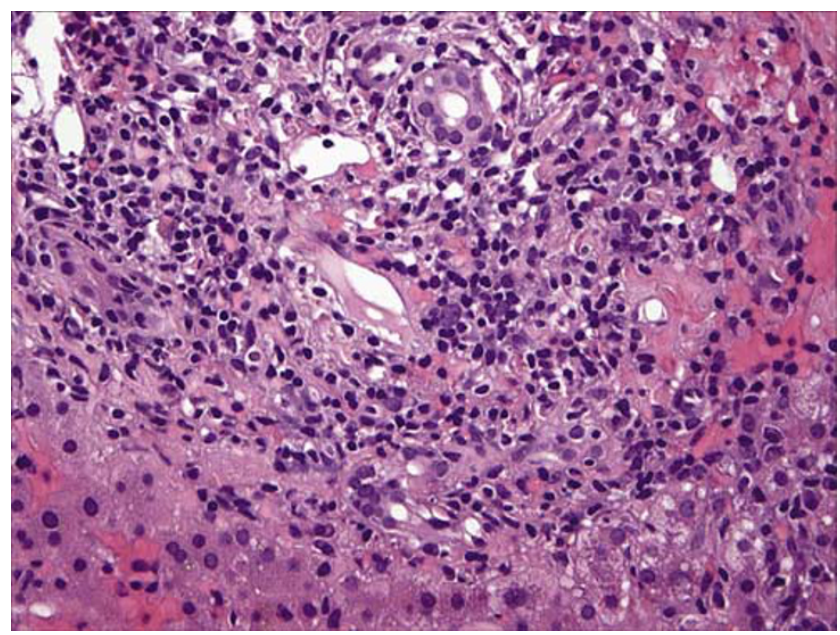

Figure 2 AIH. Interface hepatitis is variable; the portal inflammatory infiltrate consists primarily of lymphocytes with scattered plasma cells. to immunosuppressive therapy, although relapses with withdrawal of therapy are common and the disease can recur following liver transplantation. Portal plasma cell infiltrates, while on immunosuppressant therapy, are associated with relapse upon drug cessation. ${ }^{8,9}$

Centrilobular injury with prominent hepatocellular necrosis and mononuclear inflammation occurs in some cases of AIH (Figure 5), either as an isolated finding (rare) or in conjunction with periportal activity and interface hepatitis. Because the centrilobular pattern of injury can evolve over time to a more typical portal-based chronic hepatitis pattern of injury, it has been postulated that this may represent an early stage of the disease..$^{10,11}$ However, this centrilobular necroinflammatory injury pattern is not specific for AIH, and may be seen in particular in drug reactions. ${ }^{12}$

Bile duct destruction is generally not prominent in $\mathrm{AIH}$, but up to $12 \%$ of biopsies may show duct destruction, and an additional $12 \%$ show lympho-

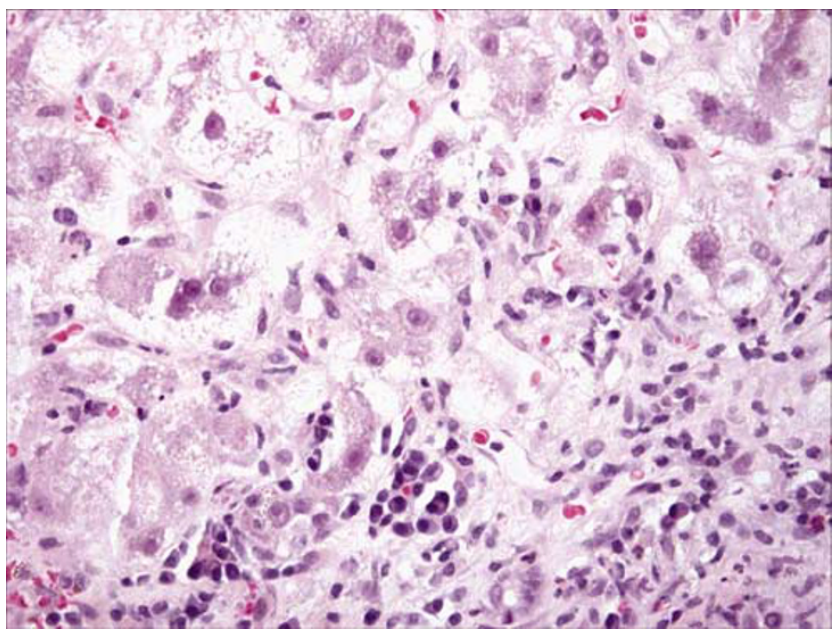

Figure $3 \mathrm{AIH}$ with prominent plasma cell infiltrate at limiting plate.

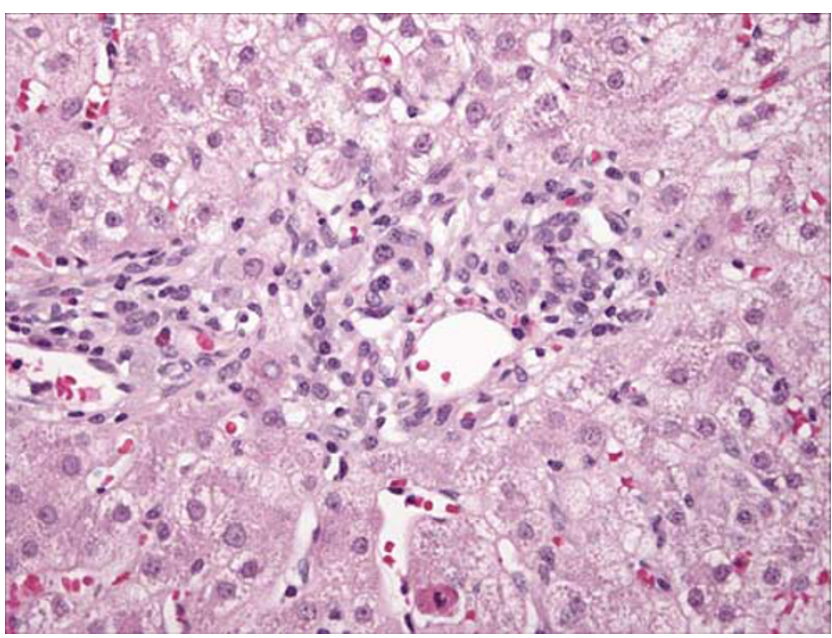

Figure $4 \mathrm{AIH}$. Necroinflammatory activity is variable and may be relatively mild. 
S18

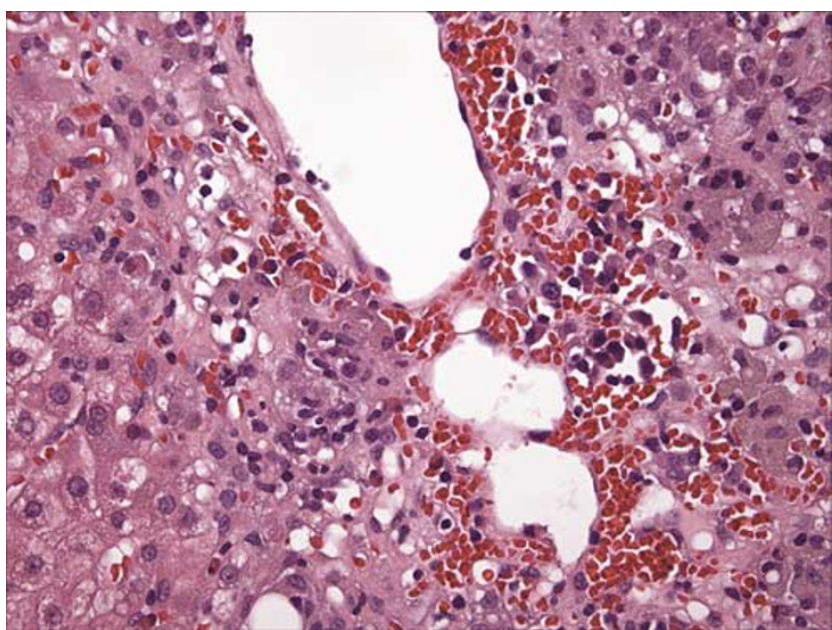

Figure $5 \mathrm{AIH}$. Centrilobular injury with prominent hepatocyte necrosis and mononuclear inflammation may be seen in some cases of AIH; in most cases, the typical portal-based inflammatory pattern of injury is also present.

cytic infiltration of bile duct epithelium without ductopenia. ${ }^{13,14}$ The histologic pattern of injury may be indistinguishable from PBC. ${ }^{15}$

\section{Scoring system}

A working classification useful in diagnosis and research has been developed by the International Autoimmune Hepatitis Group and modified in $1999 .^{4,5}$ This system (Table 2) classifies cases as definite or probable $\mathrm{AIH}$, based upon weighted parameters. In multiple reports, this system has a high degree of sensitivity $(97-100 \%)$ for the diagnosis of AIH. The system also effectively excludes AIH in patients with PSC and biliary disorders (96-100\% accuracy for exclusion of definite AIH). However, if cases considered probable AIH are included, the overall specificity is reduced. The overall diagnostic accuracy of the scoring system is roughly $90 \%$.

\section{Classification}

AIH may be subclassified based upon the autoantibody profile; such subclassification may be useful for research purposes and may define pathogenetically distinct groups, but has little application in clinical practice at the present time. Type I AIH is defined as ANA and/or SMA positive and has a bimodal age distribution with peaks between 10 and 20 and 45-70 years of age. Type 2 AIH is characterized by the presence of anti-LKM1 antibodies; the majority of these patients are young women with severe disease. However, because type $1 \mathrm{AIH}$ is much more common than type 2, most young women with severe disease will actually represent type 1 AIH. Patients with type 2 AIH present between ages 2 and 4 years, and may have ectodermal dysplasia, mucocutaneous candidiasis,
Table 2 Outline of the International Autoimmune Hepatitis Group modified scoring system ${ }^{4}$

\begin{tabular}{ll}
\hline Positive weighting & Negative weighting \\
\hline Female sex & High ALP:AST (or ALT) ratio \\
Low ALP:AST (or ALT) ratio & AMA+ \\
Hypergammaglobulinemia & Positive viral serology \\
Autoantibody+ & Positive drug history \\
Negative viral serology & High alcohol consumption \\
Negative drug history & Bile duct damage on biopsy, \\
Low alcohol consumption & other incompatible changes \\
Interface hepatitis on biopsy & \\
Concurrent immunologic disorders, \\
patient, or family
\end{tabular}

and endocrinopathies suggesting autoimmune polyglandular syndrome type $1 .{ }^{16}$ Type $3 \mathrm{AIH}$ is characterized by positivity for SLA/LP antibodies and is clinically indistinguishable from type 1.

\section{Diagnostic Difficulties}

\section{Autoantibody-negative patients}

Approximately $10-20 \%$ of AIH patients are initially seronegative for the conventional autoantibodies, which may appear after immunosuppressive therapy is begun. pANCA testing may be helpful in this subgroup of patients, and viral hepatitis $\mathrm{B}$ and $\mathrm{C}$ should be excluded before the initiation of treatment.

\section{Viral hepatitis}

Twenty to forty percent of patients with chronic HBV of HCV are persistently positive for various autoantibodies, usually at low titers $(\sim 1: 20$ or 1:40). ${ }^{3}$ Conversely, patients with AIH sometimes have a false-positive test for anti-HCV antibodies but will have undetectable HCV-RNA.

Three categories of patients with potential concurrent AIH/hepatitis C may be identified:

- patients with true $\mathrm{AIH}$ and false-positive antiHCV antibodies (undetectable HCV-RNA);

- patients with true HCV and autoantibodies at low titers, but no other signs of AIH;

- patients with true HCV and features of $\mathrm{AIH}$ including young age, female gender, high autoantibody titers ( $>1: 320$ ), hypergammaglobulinemia, and history of extrahepatic autoimmune disorders.

Distinction of chronic viral hepatitis from AIH is important, because interferon therapy can exacerbate autoimmune conditions, and corticosteroids can enhance viral replication. There has been considerable controversy about the diagnosis and management of chronic hepatitis patients with 
autoimmune markers, particularly regarding the presence of anti-LKM antibodies in HCV patients in southern Europe. It has recently been shown that anti-LKM1 antibodies directed against CYP2D6 can crossreact with HCV proteins, perhaps as a result of molecular mimicry at the B-cell level. ${ }^{17}$ The current general consensus is that interferon therapy is usually safe in HCV patients with anti-LKM1 autoantibodies. Patients with chronic viral hepatitis should be screened for autoantibodies before starting interferon therapy and monitored carefully. pANCA testing may be useful, as this autoantibody is rare in chronic hepatitis patients but relatively common in AIH.

\section{Primary biliary cirrhosis}

\section{Definition}

PBC is a chronic cholestatic liver disease of unknown etiology in which the intrahepatic bile ducts are progressively destroyed by a nonsuppurative inflammatory process. Large intra- and extrahepatic bile ducts are not affected. PBC is probably autoimmune in etiology, judging by its association with other autoimmune disorders such as Sjogren's disease and keratoconjuctivitis sicca, and may in some patients represent a generalized disorder of lacrimal, salivary, and pancreaticobiliary small duct epithelia.

\section{Epidemiology and Demographic Features}

The prevalence of PBC varies with geography, with northern Europe, especially England and Scandinavia, considered a disease hotspot. ${ }^{18}$ The disease prevalence in the US is $\sim 40$ per 100000 , with an incidence of $\sim 3$ per 100000 , and has distinctive demographic features, being found primarily in women ( $90 \%$ of patients), mostly in the fifth to seventh decades. There are no associations with particular HLA antigen haplotypes, and no clear genetic influences, although from 1 to $6 \%$ will have an affected family member. ${ }^{18}$

\section{Clinical Features}

Fifty to sixty percent of patients with PBC are asymptomatic at diagnosis ${ }^{19}$ and identified after screening tests show elevation of serum alkaline phosphatase. Overt symptoms develop in most within 2-4 years, although some are asymptomatic for years. The most common presenting symptoms are fatigue $(21 \%)$ and pruritis $(19 \%),{ }^{19}$ the latter due to the accumulation of bile salts.

The mainstay of treatment of early PBC is ursodeoxycholic acid (UDCA). At least $25 \%$ of patients with early PBC (stage 1 or 2 ) treated with UDCA will have no histologic progression over 4 years, and 25$30 \%$ will have a complete response, ${ }^{20}$ characterized by normalization of liver enzyme tests and improvement or stabilization of liver biopsy; in one study, the survival rate for patients with stage 1 or 2 disease treated for a mean of 8 years was similar to a healthy control population. ${ }^{21}$ With stage 3 and 4 disease, the outcome is not as favorable, with a median time to transplant or death of 9.3 years. Without treatment, the mean time to progression from stage 1 or 2 disease to cirrhosis is 4-6 years. In contrast to $\mathrm{AIH}$, corticosteroids are not effective in PBC.

Survival is variable, but is generally from 6 to 12 years after presentation for symptomatic patients. In one report, $26 \%$ developed liver failure by 10 years after diagnosis. ${ }^{19}$ Factors decreasing survival are jaundice, loss of bile ducts, cirrhosis, and presence of other autoimmune disorders. Liver transplantation is the only effective therapy for late-stage disease; although histologic disease recurrence is reported in up to $30 \%$ of patients, clinically significant and progressive recurrent disease is uncommon. ${ }^{22}$

\section{Diagnosis}

\section{Serum studies}

The most specific feature of PBC is the presence of antimitochondrial antibodies in the serum of $90 \%$ of patients affected. These antibodies directed to the PDC-E2 antigen, a component of the pyruvate dehydrogenase enzyme complex present on the inner mitochondrial membrane, are highly specific (96\%) for PBC. Immunohistochemical staining shows that expression of either PDC-E2 ${ }^{23}$ or a PDC-E2 mimic is increased in bile duct epithelial cells of PBC patients, and aberrant luminal expression is seen. Recent advances in bile duct immunology reveal qualitative differences in metabolic processing of PDC-E2 during apoptosis of biliary epithelial cells; thus, the biliary epithelium may attract an immune attack by the unique biochemical mechanism by which the bile duct cell handles PDC-E2. ${ }^{24}$

The presence of serum AMA indicates a specific B-cell response to this mitochondrial antigen, but specific T-cell responses directed against PDC-E2 are seen as well. ${ }^{25}$ Other circulating autoantibodies such as anti-SMA and ANA and rheumatoid factor are often present, and hypergammaglobulinemia with a selective elevation of IgM is common.

Although the search for a specific etiologic agent in PBC has to date been unsuccessful, the possibility of an infectious agent triggering the disease in a genetically susceptible host appears plausible, with a 'multiple hit' mechanism triggered by molecular mimicry between microbial and human PDC-E2 resulting in breakdown of immune tolerance. ${ }^{24}$ Proposed culprits include Novosphigobium aromaticivorans and Escherichia coli. Exposure to environmental chemicals has also been proposed but no specific agents have been strongly implicated. 
Other disease-specific antibodies that may be detected in PBC include the nuclear core protein gp210, which appears to be highly specific (99\%) for PBC and may portend a more severe course. This autoantibody is found in $10-40 \%$ of AMApositive patients and up to $50 \%$ of AMA-negative patients. $^{26}$

\section{Histopathology}

The characteristic lesion of PBC is the so-called florid duct lesion (Figure 6), sometimes also called chronic nonsuppurative destructive cholangitis. ${ }^{27}$ Interlobular bile ducts $40-80 \mu \mathrm{m}$ in diameter are typically involved, and canals of Hering are also destroyed at all stages of the disease. ${ }^{28}$ In early-stage $\mathrm{PBC}$, the diagnostic lesions may be focal and may not be sampled on needle biopsy. The three components of the florid duct lesion are inflammation, injury to bile duct epithelial cells, and disruption of the bile duct basement membrane. The inflammatory infiltrate is composed of lymphocytes, scattered eosinophils, macrophages, and a variable number of plasma cells, and is intimately associated with the bile duct. The macrophages may be dispersed throughout the portal inflammatory infiltrate or may be aggregated into loose clusters or occasionally into well-formed granulomas. Granulomas and Kupffer cell aggregates may be present in the lobule. In early stages, the inflammatory infiltrate is largely confined to the portal tract. The biliary epithelial cells of injured bile ducts are swollen, and focally stratified, and may be vacuolated. Lymphocytes commonly infiltrate bile duct epithelium. The basement membrane becomes disrupted and fragmented (Figure 7), best visualized on PAS stain. Lytic necrosis, not apoptosis, appears to account for most of the biliary epithelial loss. ${ }^{29}$ In small portal tracts, bile ducts are often absent and seem to have vanished without a trace, although aggregates of lymphocytes or PAS-positive basement membrane material may mark their former location. Canalicular cholestasis is not a feature of early-stage PBC.

As the duct destruction progresses, bile ductular proliferation accompanied by fibrosis develops at the periphery of portal triads, and portal tracts enlarge by this process of biliary piecemeal necrosis. In some cases, the inflammatory infiltrate spills over into the adjacent parenchyma, and lymphocytic interface hepatitis may mimic chronic hepatitis. At this stage, the changes of chronic cholestasis begin to appear, with swollen and rarefied periportal hepatocytes and accumulation of copper. As periportal fibrosis progresses, portal-portal fibrous bridges are formed. Bile ductular proliferation often subsides in late-stage PBC, and in the cirrhotic stage little ductular or ductal epithelium can be identified. The cirrhosis has a typical biliary pattern, in which the nodules have an irregularly shaped 'jigsaw puzzle piece' profile (Figure 8).

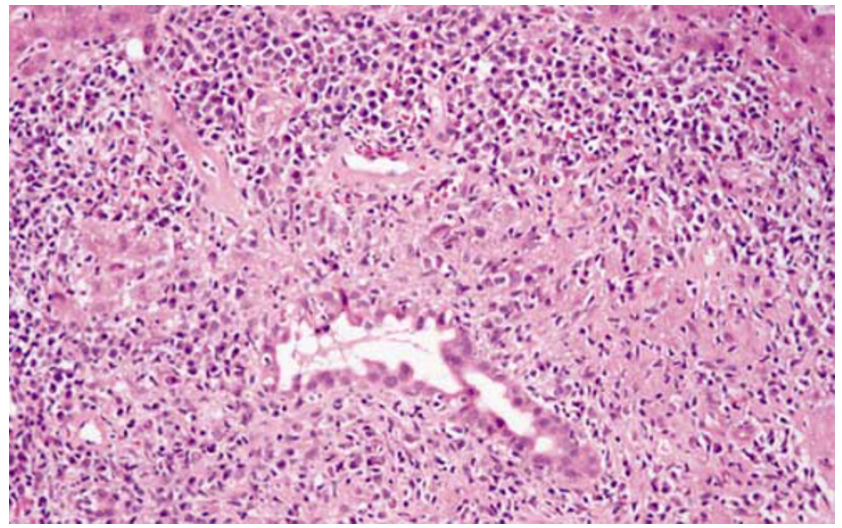

Figure 6 PBC. Florid duct lesion with bile duct injury with prominent granulomatous inflammation.

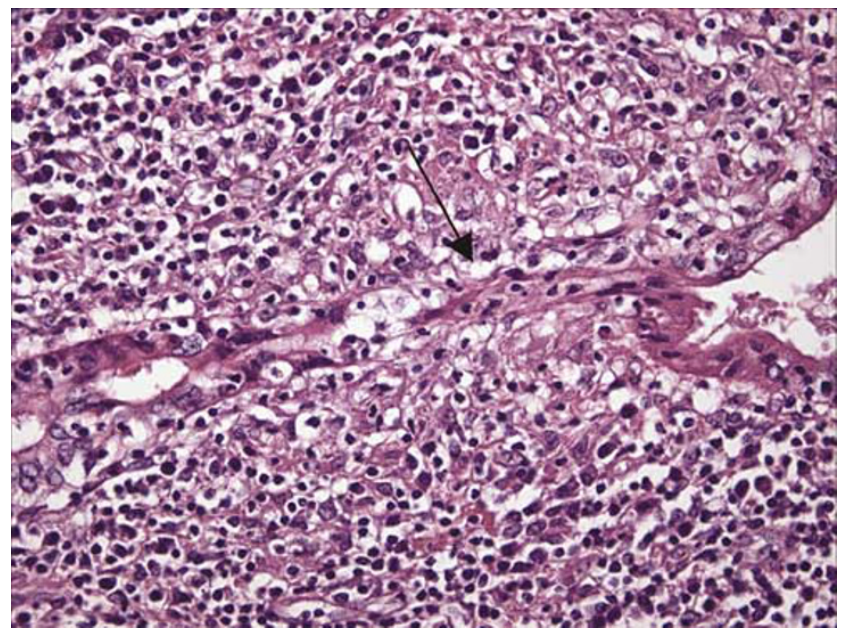

Figure 7 PBC. Duct destruction is segmental and may be focal (arrow) in early-stage PBC. Note prominent periductal mononuclear inflammatory infiltrate.

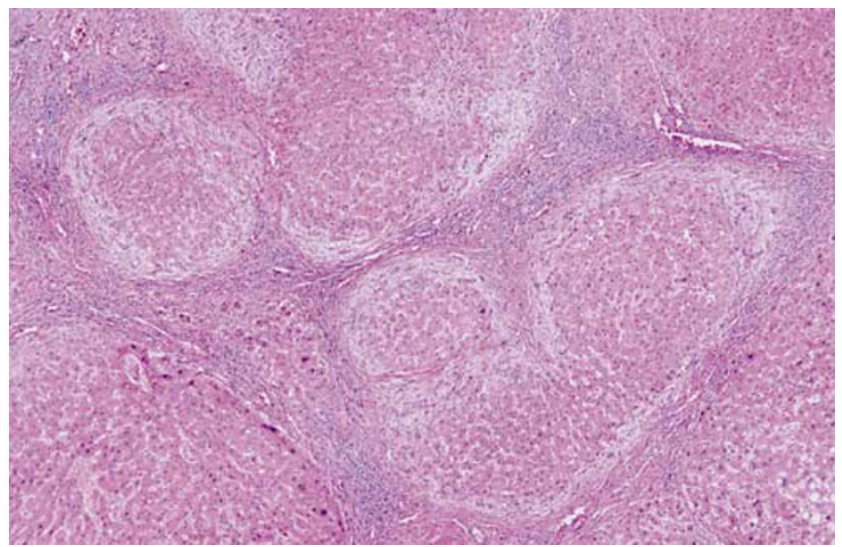

Figure 8 PBC. Cirrhosis in PBC has a typical biliary cirrhosis pattern, with irregular nodules with peripheral pallor due to cholate stasis.

\section{Criteria for diagnosis}

Diagnosis rests upon a combination of clinical, serologic, and histologic features, including chole- 
static serum enzyme pattern, serum AMA, and compatible histology. A probable diagnosis of PBC requires two of the following three criteria, and a definite diagnosis requires three:

- + AMA;

- elevated liver enzymes, usually alkaline phosphatase, for over 6 months; and

- compatible liver biopsy.

A more detailed scoring system similar to that used for AIH has been proposed but not well validated; $;^{30}$ a number of weighted parameters are assessed, including:

- cholestatic serum enzyme pattern, as evidenced by alkaline phosphatase/ALT ratio;

- elevated serum IgM;

- AMA titer greater than 1:40, detected by IF or PBC-specific AMA-M2 detected by ELISA or IB;

- florid bile duct lesion.

\section{Diagnostic difficulties}

The differential diagnosis for PBC depends on the stage of the disease. In stage 1 and 2 disease, portal inflammation, piecemeal necrosis, and bile ductular proliferation may mimic chronic hepatitis, particularly hepatitis C. Bile duct damage is less prominent in chronic hepatitis and bile duct loss is rarely seen, but lymphocytic infiltration of bile duct epithelium is often a feature of hepatitis C. Immunostaining for cytokeratin 7 shows absence of central interlobular bile ducts and lack of a lumen in preserved ducts, presumably owing to cell swelling, in $\mathrm{PBC}$ but not in chronic hepatitis. ${ }^{31}$ Clinical information such as antimitochondrial antibody status and serologic markers for viral hepatitis is helpful in most cases.

Distinction of PBC from those cases of sarcoidosis with destruction of bile ducts by granulomas may be difficult (Table 3). In a study of 100 cases of hepatic sarcoidosis, $58 \%$ of the biopsies showed evidence of cholestasis, generally feathery degeneration and increased copper storage. ${ }^{32}$ Nineteen of these biopsies had bile duct lesions similar to those seen in PBC. The granulomas of sarcoidosis tended to be better formed and more numerous than those of PBC (Figure 9). The lack of AMA positivity and the presence of pulmonary involvement also favor a diagnosis of hepatic sarcoidosis. Of note, sarcoidosis may also cause intrahepatic biliary strictures that have cholangiographic features resembling PSC. ${ }^{33}$

\section{The Surgical Pathology Report in PBC}

The following features may be useful to note in the surgical pathology report in PBC:

- Description of bile duct lesion: granulomatous, lymphocytic, loss of bile ducts.

- Nature of portal inflammatory infiltrate: are plasma cells prominent?

- Presence of interface hepatitis.

- Bile ductular reaction.

- Lobular activity: lymphocytes, granulomas, Kupffer cell aggregates, hepatocyte injury.

- Cholestasis: canalicular bile plugs (rare), feathery degeneration, Mallory's hyaline (late stage)

- Extent of fibrosis (stage).

\section{Histologic Staging of PBC}

The value of histologic staging in assessing prognosis in early-stage PBC is debatable, given the lack of uniformity of duct loss in the liver in this disease. However, the presence of portal-portal bridging fibrosis on biopsy has been shown to be a poor prognostic sign. Several staging schemes have been described, and there is little practical difference

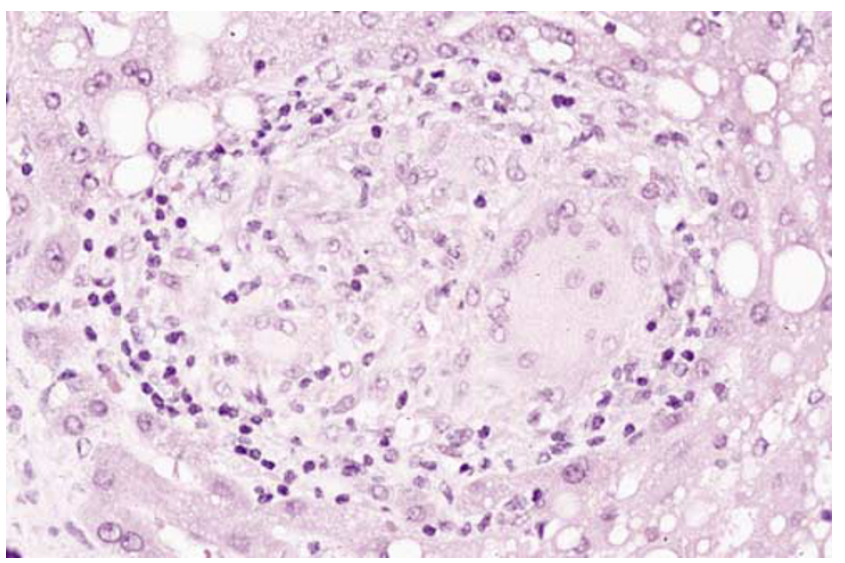

Figure 9 Hepatic sarcoidosis. Granulomas in hepatic sarcoidosis are usually more numerous, better formed, and randomly distributed compared to those seen in PBC.

Table 3 Comparison of histologic features of PBC, PSC, chronic hepatitis, and sarcoidosis

\begin{tabular}{lllll}
\hline Feature & PBC & PSC & Chronic hepatitis & Sarcoidosis \\
\hline Chronic cholestasis & Prominent, late & Prominent, late & Trace, late & Variable \\
Copper storage & Variable & Variable & Trace & Variable \\
Duct loss & Extensive & Extensive & Rare & Variable \\
Granulomas & Variable & Rare & Key feature & Key feature \\
Interface hepatitis & Variable & Variable & & Absent
\end{tabular}


Table 4 Staging of primary biliary cirrhosis

\begin{tabular}{|c|c|c|c|}
\hline Stage & Ludwig system ${ }^{35}$ & Scheuer system ${ }^{34}$ & Features \\
\hline 1 & Portal & Florid duct lesion & Bile duct damage and portal inflammation \\
\hline 2 & Periportal & Ductular proliferation & $\begin{array}{l}\text { Expanded portal tracts with bile ductular reaction, periportal } \\
\text { inflammation, and biliary piecemeal necrosis }\end{array}$ \\
\hline 3 & Septal & Fibrosis & Periportal fibrosis with portal-portal bridging; loss of bile ducts \\
\hline 4 & Cirrhosis & Nodular cirrhosis & Irregular parenchymal nodules with bridging fibrous scars \\
\hline
\end{tabular}

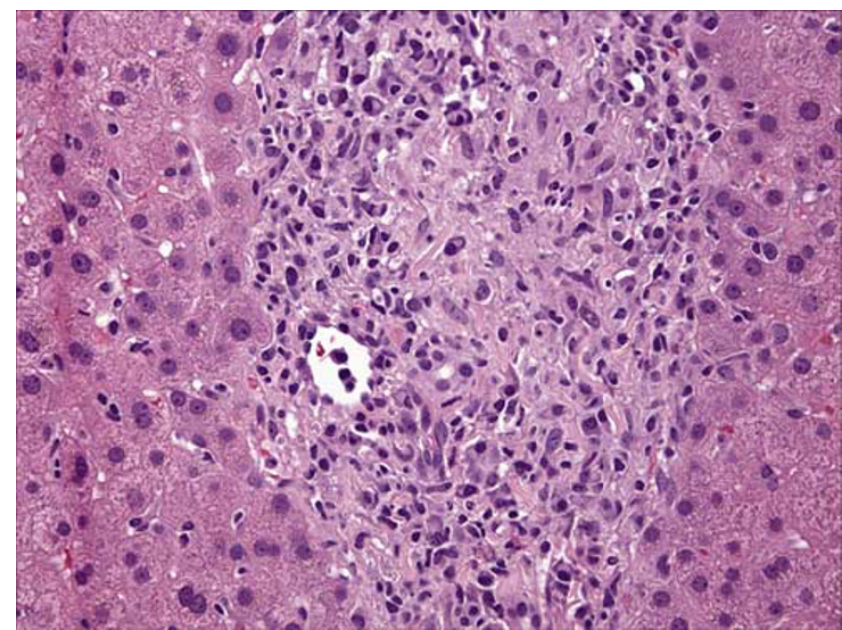

Figure 10 PBC, stage I, with bile duct destruction without portal fibrosis.

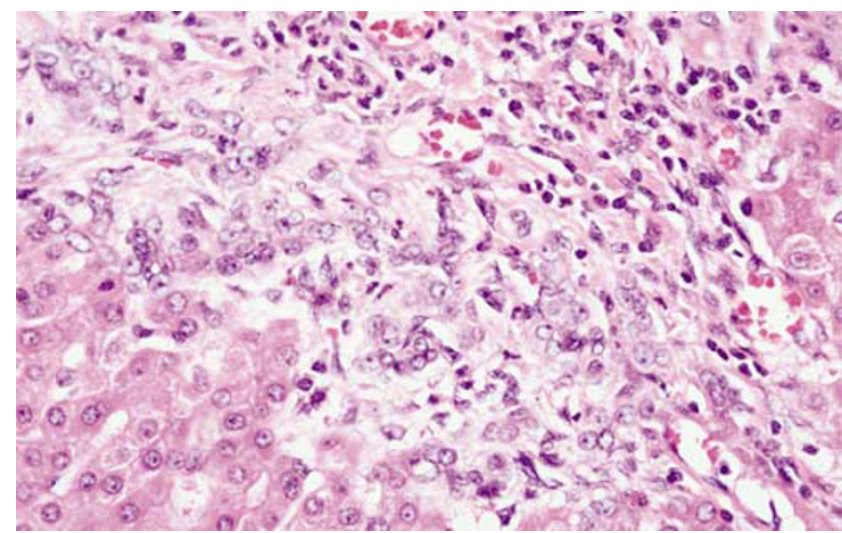

Figure 11 PBC, stage II, with bile ductular reaction and periportal fibrosis.

between the two that are most commonly employed (Table 4), those described by Scheuer ${ }^{34}$ and Ludwig. ${ }^{35}$ In stage 1 disease, damage to interlobular bile ducts is seen in the form of the florid duct lesion (Figure 10). In stage 2, the effects of duct injury result in extension of the process to involve the periportal areas, and ductular reaction, probably representing a compensatory reaction to bile duct loss, is prominent (Figure 11). Stage 3 is characterized as a scarring or precirrhotic stage, with bridging fibrosis (Figure 12). Stage 4 is cirrhosis (Figure 13).

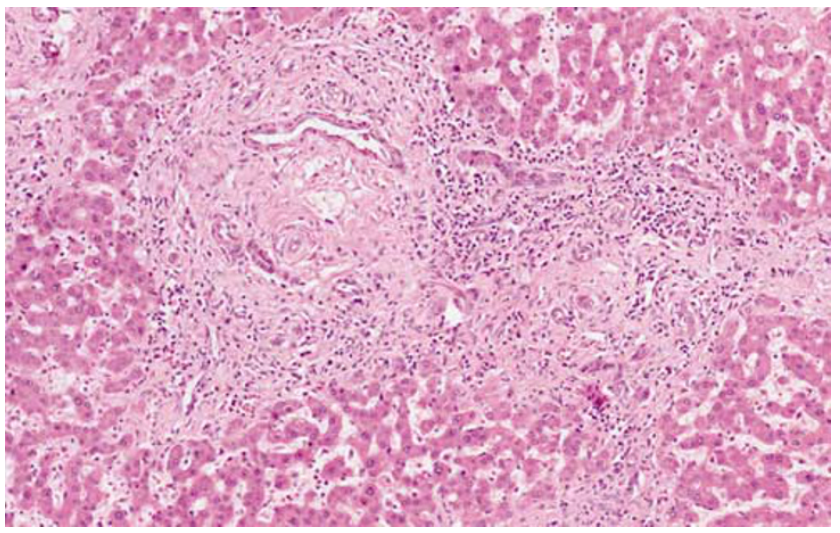

Figure 12 PBC, stage III, with portal-portal bridging fibrosis.

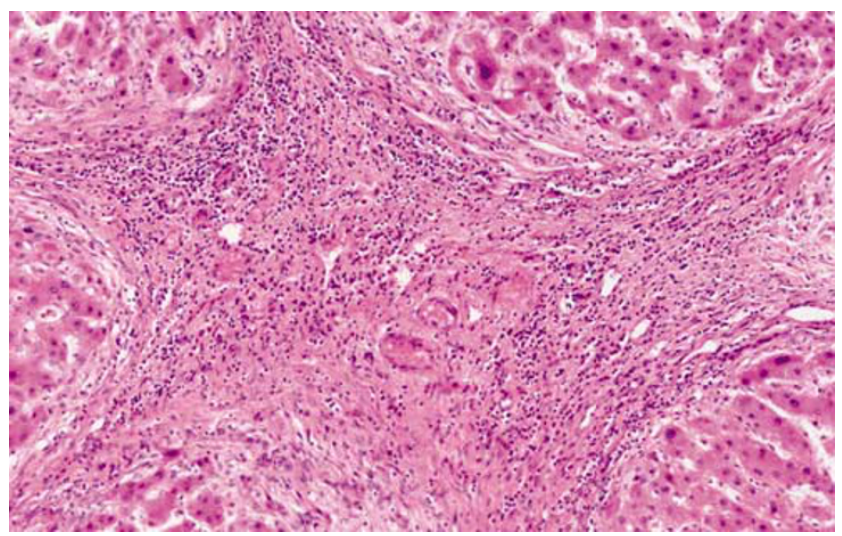

Figure 13 In PBC, stage IV, the cirrhotic liver often lacks small bile ducts and there is little residual bile ductular reaction.

\section{Primary sclerosing cholangitis}

\section{Definition}

PSC is a chronic cholestatic disorder characterized by fibrosis and inflammation of the extra- and intrahepatic biliary tree.

\section{Epidemiology and Demographic Features}

In contrast to PBC, PSC is a disease of men, with a male predominance of 2:1. The median age of onset is low (30 years) but there is an extraordinarily wide age range of 1-90 years. PSC is slightly less common 
than PBC, and is rare in regions with a low prevalence of inflammatory bowel disease. The prevalence of PSC in the USA is estimated as 1-4 cases/100 000 population, ${ }^{36}$ but this is likely to be an underestimate.

The association of PSC with ulcerative colitis remains an enigma. Approximately $70 \%$ of patients with PSC have ulcerative colitis. Conversely, 3$7.5 \%$ of patients with ulcerative colitis have PSC. The ulcerative colitis typically involves a majority of the colon, but often has a relatively mild clinical course. Patients with PSC and UC may be at even higher risk for adenocarcinoma of the colon than the usual patient with UC, ${ }^{37,38}$ and patients with PSC may be at higher risk for pancreatic carcinoma. ${ }^{38}$ Like PBC, PSC is considered to be a disease of autoimmunity, and a marked increase in prevalence of HLA antigens B8 and DR3 has been found in patients with PSC. ${ }^{36}$ The HLA-DR3, DQ2 heterozygous genotype may be associated with more rapid disease progression. ${ }^{39}$ The HLA B8, DR3 haplotype has been associated with a number of autoimmune diseases such as AIH, thyroiditis, celiac disease, and myasthenia gravis.

\section{Clinical Features}

The typical PSC patient is a young male with IBD who presents with biochemical and clinical evidence of cholestasis (Table 5). Almost half are asymptomatic at diagnosis; ${ }^{40}$ symptomatic patients may present with jaundice, pruritis, and right upper quadrant pain.

The natural history of PSC is more variable than that of PBC. For the most part PSC is a progressive disease, with over $90 \%$ of patients with stage 2 (periportal disease) progressing over 5 years. ${ }^{41}$ Because of the presence of bile duct strictures and the formation of biliary stones and sludge, PSC is commonly complicated by bacterial cholangitis. The development of cholangiocarcinoma is a major complication, seen in up to $16 \%$ of PSC patients. Accurate diagnosis of cholangiocarcinoma remains a problem in many cases, as tumor may be indistinguishable from stricture on cholangiogram and accurate cytologic diagnosis from bile duct brushings may be exceedingly difficult. Elevated CA19-9 levels, if greatly elevated, may be of utility, although considerable overlap with PSC without cancer is seen.

\section{Diagnosis}

Diagnosis of PSC is established on radiographic grounds, by the cholangiographic appearance of beading and irregularity of the biliary system and indeed cholangiography is the diagnostic gold standard for PSC. Magnetic resonance cholangiography is increasingly used for evaluation of PSC.

\section{Serologic studies}

Although serum antineutrophilic antibodies (ANCA) are present in $80 \%$ of PSC patients, this test is considered of limited use in diagnosis because of overlap with AIH.

\section{Histopathology}

Liver biopsy is undertaken to rule out other causes of liver disease and for staging purposes. Most hepatologists understand that liver biopsy alone is rarely diagnostic in this disease, as the disease process may be patchy in the liver and small intrahepatic bile ducts may not show diagnostic changes. ${ }^{42}$

The diagnosis of small duct PSC is made in patients without large duct involvement who have inflammatory bowel disease and cholestatic liver disease with morphologic features of PSC on liver biopsy. Although it has been speculated that this variant may represent an earlier stage of PSC, small duct PSC does not seem to progress rapidly to large duct PSC $^{43}$ and may be associated with a more benign long-term prognosis ${ }^{44}$ and much lower risk of cholangiocarcinoma.

A wide variety of morphologic changes that reflect the varying levels of duct involvement are seen in

Table 5 Clinicopathologic features of primary biliary cirrhosis and primary sclerosing cholangitis

\begin{tabular}{|c|c|c|}
\hline & Primary biliary cirrhosis & Primary sclerosing cholangitis \\
\hline Age & Median age 50 years $(30-70)$ & Median age 30 years \\
\hline Gender & $90 \%$ female & $70 \%$ male \\
\hline Clinical course & Progressive & Unpredictable but progressive \\
\hline \multirow{4}{*}{ Associated conditions } & Sjogren's syndrome $(70 \%)$ & Inflammatory bowel disease \\
\hline & Scleroderma (5\%) & Pancreatitis (up to $25 \%$ ) \\
\hline & Rheumatoid arthritis & Idiopathic fibrosing diseases (retroperitoneal fibrosis) \\
\hline & Thyroid disease $(20 \%)$ & Inflammatory bowel disease \\
\hline \multirow{3}{*}{ Serology (1) } & $95 \%$ AMA+ & $0-5 \%$ AMA+(low titer) \\
\hline & $20 \%$ ANA+ & $6 \%$ ANA+ \\
\hline & $60 \%$ ANCA+ & $82 \%$ ANCA+ \\
\hline Radiology & Normal & Strictures and beading of large bile ducts; 'pruning' of smaller ducts \\
\hline Duct lesion & Florid duct lesion; loss of small ducts & Concentric periductal fibrosis; loss of small ducts \\
\hline
\end{tabular}


PSC. Unfortunately, the classic lesion of periductal concentric 'onion-skinning' fibrosis is rarely seen in needle biopsy specimens. This pattern of fibrosis often has only a sparse inflammatory infiltrate (Figure 14). The bile duct epithelium is atrophic and epithelial cells are shrunken, with pyknotic nuclei. A rounded scar often marks the site of a destroyed bile duct (Figure 15). Alternatively the smaller interlobular bile ducts may vanish without a trace, ${ }^{45}$ especially in pediatric cases, and residual scars are not identified. Interlobular bile ducts may be distorted in a subtle fashion, with only angulated profiles and irregular spacing of duct cell nuclei to indicate epithelial injury. The bile duct epithelium may be vacuolated and focally infiltrated by lymphocytes. The portal inflammatory infiltrate is usually sparse and primarily made up of mononuclear inflammatory cells, with scattered eosinophils. Early in the disease portal eosinophils may be unusually prominent. Portal granulomas are distinctly unusual although a granulomatous response to leakage of bile products does occur in 3-4\% of biopsies (Figure 16). ${ }^{46}$ Lobular changes early in the

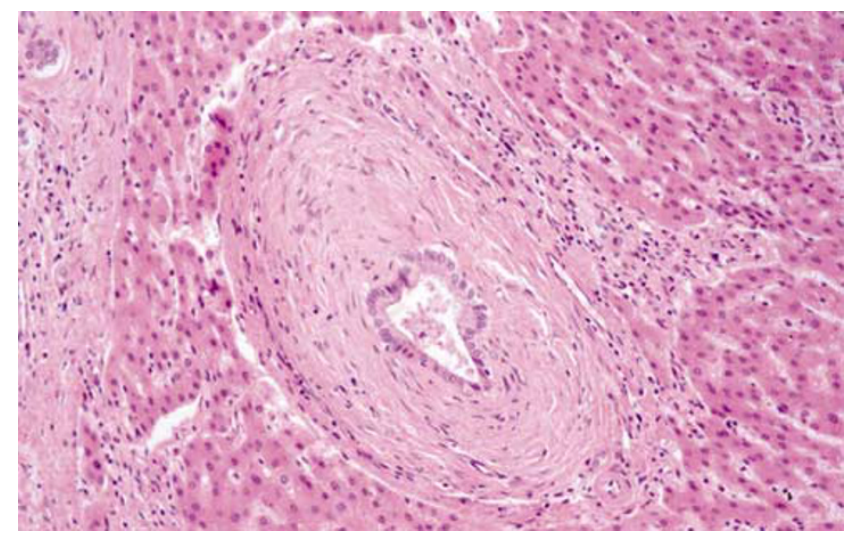

Figure 14 PSC. Concentric periductal fibrosis with bile duct distortion.

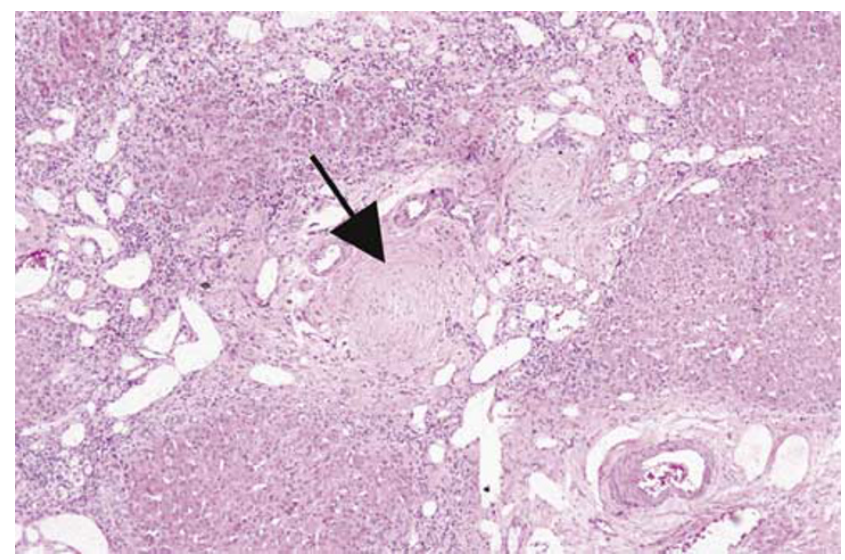

Figure 15 PSC. Nodular almost acellular scars mark areas of destroyed bile ducts. disease are generally minor; late in the disease, changes of chronic cholestasis are common (Figure 17). The pattern of fibrosis is similar to that seen in PBC.

Changes of large duct obstruction are often superimposed on small duct changes of PSC. Bile ductular reaction is common, and periductal edema and acute cholangitis may also be seen, especially in the setting of bacterial cholangitis. Canalicular bile plugs may be present.

The large bile ducts most commonly involved by PSC are, of course, not present in needle-biopsy specimens. In the liver explant, larger intrahepatic bile ducts are often dilated and contain inspissated bile plugs and sludge (Figure 18). The walls of large bile ducts are fibrotic and contain chronic inflammatory cells. Reactive and hyperplastic changes in entrapped peribiliary gland $\mathrm{s}^{47}$ can pose a diagnostic dilemma in the evaluation of surgical biopsies of these large ducts to rule out cholangiocarcinoma. Clues to malignancy are unequivocal perineural invasion, cribriform glandular structures, and pronounced nuclear pleomorphism and atypia. ${ }^{48}$ The

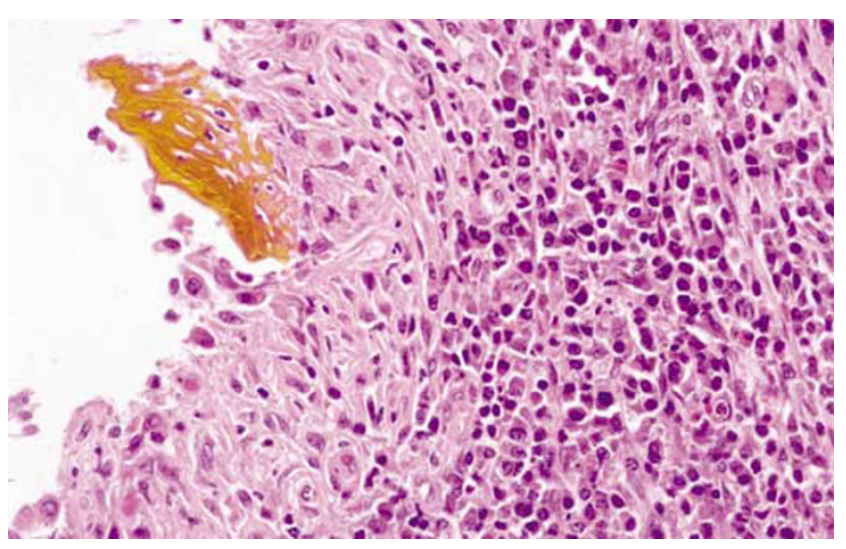

Figure 16 PSC. A granulomatous response to extravasated bile may be seen in $3-4 \%$ of PSC biopsies.

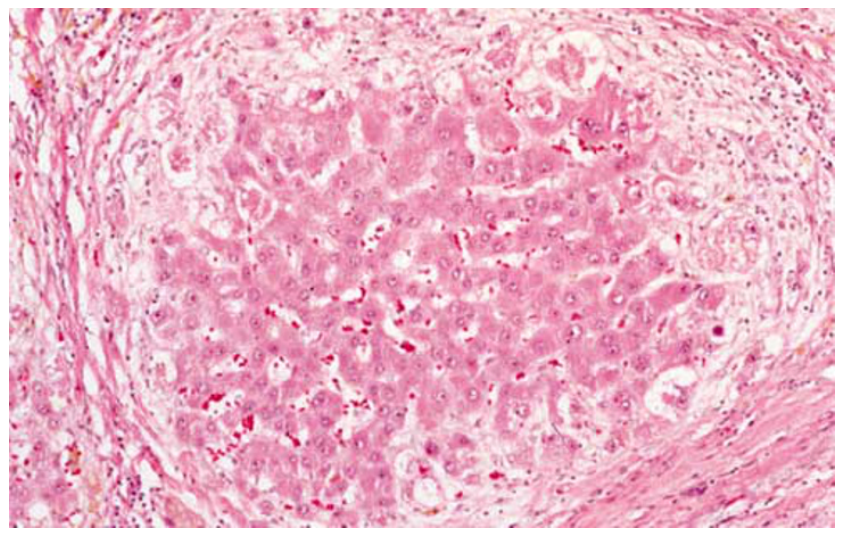

Figure 17 PSC. Marked chronic cholestasis with feathery degeneration owing to accumulation of bile salts is common in latestage PSC. 


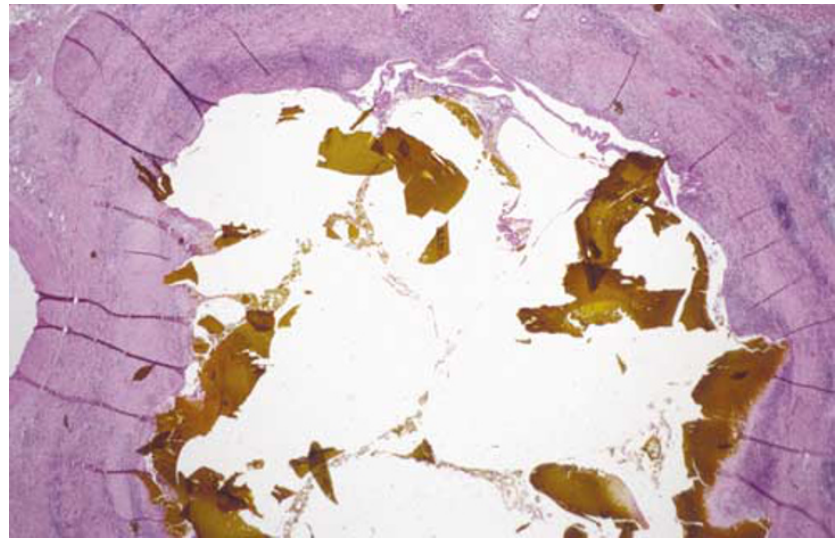

Figure 18 PSC. Large bile ducts in PSC show a marked chronic inflammatory infiltrate, erosion of biliary epithelium, and may contain inspissated bile.

peribiliary glands are grouped in lobular clusters, although this may be difficult to discern in the fibrotically distorted specimen.

The histologic staging schemes used for PSC are similar to those used for PBC (Table 4).

\section{Diagnostic difficulties}

As for PBC, the differential diagnosis for PSC changes with disease stage. Histologic overlap with $P B C$ is occasionally a problem, although knowledge of the clinical setting, serologic tests, and radiographic appearance generally results in resolution. The portal inflammatory infiltrate in PSC is usually sparser than that seen in PBC, and florid duct lesions are not seen.

Chronic large duct obstruction may be difficult to distinguish from PSC, as extrahepatic obstruction from bile duct strictures is part of the pathologic process in this disease. Periductal fibrosis, bile ductular proliferation, and cholestasis are seen in both obstruction and PSC. However, in large duct obstruction from other causes, loss of interlobular bile ducts does not generally occur, and atrophic changes in ductal epithelium do not occur. The presence of numerous eosinophils in the portal inflammatory infiltrate also favors PSC.

Recurrent pyogenic cholangitis is a bacterial form of cholangitis that occurs almost exclusively in patients of Asian origin and is not likely to be confused with PSC. However, like PSC, many of the histologic features in this disorder are a result of bile stasis. Biliary parasites are present in some but not all cases. Repetitive bacterial infection and pigment stone formation result in biliary strictures, which in turn predispose to infection and more stone formation. Large intrahepatic ducts are scarred, thickened, and contain biliary sludge and stones. Microscopically, fibrosis and inflammation are present in the walls of large ducts. Small portal tracts show acute cholangitis, portal edema, and varying degrees of fibrosis. ${ }^{49}$ Cholangiocarcinoma arising in large stone-bearing ducts may complicate the disease.

\section{Secondary sclerosing cholangiopathies}

Other causes of biliary strictures are intrahepatic artery chemotherapy, immunodeficiency syndromes, and Langerhans' cell histiocytosis. Hepatic artery infusion of floxuridine for treatment of hepatic metastases from colorectal carcinoma has been associated with a sclerosing cholangitis-like lesion resulting in hepatic failure. The etiology of these changes may be ischemic rather than toxic, as the bile ducts are supplied by the hepatic artery ${ }^{50,51}$ Although treatment regimens now attempt to minimize the risk of this complication, the majority of patients receiving this therapy develop bile duct abnormalities on hepatic imaging. ${ }^{51}$

Langerhans' cell histiocytosis may present with isolated hepatic involvement or with involvement of other organ systems, most commonly lymph node and skin. In one study, seven of nine cases demonstrated injury to small and medium intrahepatic bile ducts by infiltrating Langerhans' cells. ${ }^{52}$ Concentric periductal fibrosis similar to that of PSC was a feature of most cases, and bile ductular proliferation was often prominent. Of note, two cases with a PSC-like pattern of injury had no detectable Langerhans' cells in the liver, and the diagnosis was established by biopsy of extrahepatic sites.

Infectious cholangiopathies may also mimic PSC. The most common infectious agents associated with this pattern of hepatic injury are cytomegalovirus and cryptosporidium, seen primarily in the AIDS population but now rare in the era of effective HIV therapy.

Some children with primary immunodeficiency develop sclerosing cholangitis. While many of these cases are undoubtedly related to persistent biliary tract infections, in others no infectious agent has been demonstrated. In one report of 56 children with PSC, eight (14\%) had a primary immunodeficiency syndrome, associated with cryptosporidial infection in three, cytomegalovirus in three, and no demonstrable organisms in two. ${ }^{53}$

\section{Overlap and outlier (variant) syndromes}

A sizeable percentage of cases of autoimmune liver disease that generally fit into one diagnostic category will show clinical, serologic, or histologic features more characteristic of another type of autoimmune liver disease. When overlap in all three areas (clinical features, serologic profile, and histopathology) is present, the diagnosis of an overlap syndrome should be considered. However, it should be noted that it is controversial whether these overlap syndromes are distinct entities or variants of the major autoimmune hepatopathies, and stan- 
Table 6 Variants of autoimmune liver disease ${ }^{73}$

\begin{tabular}{lll}
\hline Overlap syndromes & Outlier syndrome & Sequential syndromes \\
\hline AIH-PBC & AIC $^{\mathrm{a}}$ & $\mathrm{AIH} \Leftrightarrow \mathrm{PBC}$ \\
AIH-PSC & & $\mathrm{AIH} \Leftrightarrow \mathrm{PSC}$ \\
AIH-AIC $^{\mathrm{a}}$ & & \\
\hline
\end{tabular}

${ }^{\mathrm{a}}$ Autoimmune cholangitis.

dardization of diagnostic criteria and terminology is lacking.

The term 'overlap syndrome' is used primarily to describe variant forms of autoimmune liver disease that present with both cholestatic and hepatitic features that do not fit readily into the usual diagnostic categories, ${ }^{54,55}$ and which generally have overlapping characteristics of $\mathrm{AIH}+\mathrm{PBC}$ or $\mathrm{AIH}+$ PSC (Table 6).

In addition to cases with simultaneous characteristics of two autoimmune liver diseases, transitions between $\mathrm{PBC} \Leftrightarrow \mathrm{AIH}$ and $\mathrm{AIH} \Leftrightarrow \mathrm{PSC}$ have been described and termed sequential syndromes.

\section{Autoimmune Cholangitis (AMA-Negative PBC): an Outlier Syndrome?}

Although this entity lacks uniform diagnostic criteria, the term 'AMA-negative $P B C$ ' or 'autoimmune cholangitis' (AIC) has generally been applied to cases that are clinically, histologically (Figure 19), and biochemically compatible with PBC except for the lack of identifiable antimitochondrial antibodies; serum ANA and anti-SMA may be present in high titers. Because this entity closely resembles PBC except in its autoantibody profile, it has been termed an 'outlier syndrome' rather than an overlap syndrome. ${ }^{56}$ More sensitive testing using cloned mitochondrial antigens such as a triple-hybrid recombinant molecule may identify AMA in some patients previously thought to be seronegative. In one study of this newly developed ELISA assay, AMA were detected in $73 \%$ of $30 \mathrm{AC}$ patients, but in none of 316 negative controls. ${ }^{57}$

In retrospective studies, no significant differences between patients with PBC and these AMA-negative patients have been described, ${ }^{58-62}$ although a prospective study describing 20 patients with autoimmune cholangitis reports that these patients have higher serum levels of AST and bilirubin and lower serum IgM than patients with classic PBC. ${ }^{63}$ Antibodies to carbonic anhydrase are present in the serum of patients with autoimmune cholangitis in some studies, but have not been discriminatory in others. ${ }^{6,65}$ However, other investigators have postulated that AIC represents a transient state between two autoimmune liver diseases, or a heterogeneous category of disorders. ${ }^{63}$ Supporting this hypothesis is the observation that of the 15 patients diagnosed prospectively with autoimmune cholangitis with

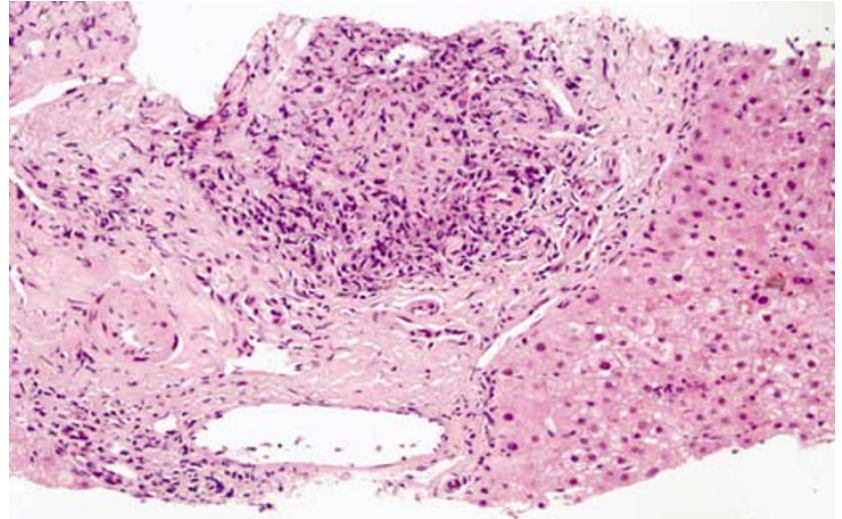

Figure 19 Autoimmune cholangitis. Florid duct lesion with granulomatous destruction of bile duct typical of PBC in a case of AIC.

biopsies reported in one study, six had a PBC-like and seven had a PSC-like pattern of injury. CD3 counts may be higher in biopsies from autoimmune cholangitis patients compared to PBC patients, but significant differences in other inflammatory cell types are not seen. ${ }^{66}$ AMA-negative patients were slightly younger in one study (50 vs 55 years) but were otherwise indistinguishable. ${ }^{58}$ Although data are largely lacking, it is thought that the response to UDCA therapy in these patients is the same as for those who are AMA-positive, and there are accordingly no differences in the treatments prescribed for these two groups at the present time.

It remains a matter of discussion whether AIC is a separate entity from PBC; most likely, the two represent one disease differing only in its autoantibody pattern. Depending on the cohort of patients, AIC may comprise a diverse group of disorders including atypical PBC, small duct PSC, idiopathic adulthood ductopenia, and transitional stages of autoimmune hepatopathies.

Overlap of AIC with AIH has been reported. ${ }^{67}$

\section{AIH-PBC Overlap}

Although it may be difficult to distinguish AIH from PBC on histologic grounds, accurate diagnosis is important because treatment for $\mathrm{AIH}$ differs from that for PBC. Difficulties arise because the portal inflammatory infiltrate of PBC often contains numerous plasma cells, and infiltration of bile duct epithelium by lymphocytes is not uncommon in AIH, if looked for, and some degree of bile duct injury is often present. Although nondestructive bile duct lesions are quite common in $\mathrm{AIH}$, duct loss is relatively uncommon, and granulomatous bile duct destruction is not seen. Serum alkaline phosphatase, cholesterol, and IgM levels are elevated to higher levels in PBC. To add to the problem, some patients with clinical and histologic features of AIH will have serum anti-mitochondrial antibodies. In some 
cases, this is caused by misreading of immunofluorescence-type tests (confusing anti-LKM antibodies with antimitochondrial antibodies). In other patients, however, the AMA is truly positive, but usually in low titer. Serologic markers may not be definitive in such cases, as patients with PBC may have a positive ANA and patients with AIH may have a low titer AMA. Liver biopsies in such cases show features of both PBC (granulomatous inflammation and bile duct lesions) and AIH (piecemeal necrosis and spotty hepatocyte necrosis) (Figure 20). ${ }^{68}$ In addition to these cases with 'overlapping' simultaneous features of both diseases, rare patients who switch from one disease to another over time are reported. ${ }^{69}$

The existence of this overlap syndrome between $\mathrm{PBC}$ and $\mathrm{AIH}$, first reported around 30 years ago, ${ }^{70}$ is generally recognized, although investigators disagree over exact classification. Some research$\mathrm{ers}^{55}$ consider these patients to have PBC, based on duct destruction and presence of AMA, and have proposed that these cases be classified as 'PBC, hepatitic form'. Others have concluded that overlap of PBC and AIH is not rare, and that combination therapy with UDCA and steroids is indicated in most of these patients to obtain a biochemical response. ${ }^{54}$ Because of the observation that some patients diagnosed with PBC have a flare of hepatitic activity when treated with UDCA, it has been proposed that response to UDCA may unmask the hepatitis component in overlap patients. ${ }^{54}$ Further complicating the issue, some investigators suggest that features of $\mathrm{AIH}$ in $\mathrm{PBC}$ may be transient. ${ }^{71}$

Up to $10 \%$ of AIH or PBC patient may belong in this overlap category, but because reported criteria vary among studies, comparison is difficult. In one

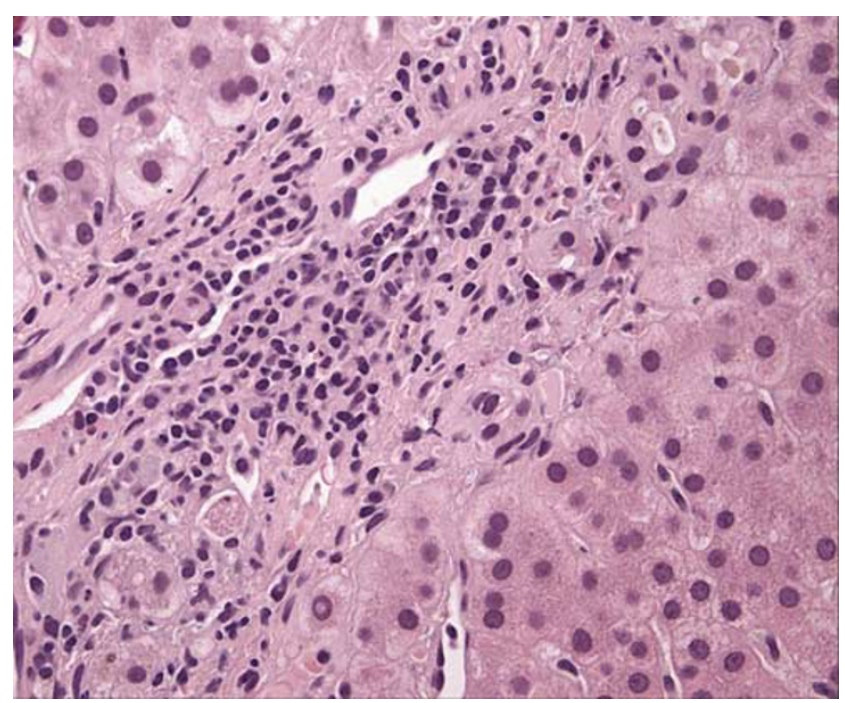

Figure 20 PBC-AIH overlap syndrome. Bile duct loss with relatively mild interface hepatitis in a case with serologic, histologic, and clinical features of both AIH and PBC. study, at least two of the following criteria for $\mathrm{AIH}$ and PBC were required: ${ }^{54}$

AIH: $\quad$ ALT $>5$ times upper limit of normal;

IgG $>2$ times upper limit of normal, or antiSMA positive;

Chronic hepatitis pattern of injury on liver biopsy.

PBC: Alkaline phosphatase $>2 \times$ upper limit of normal;

AMA + ;

Florid duct lesion on liver biopsy.

Because ANA are found in high rates in PBC patients, this autoantibody is not considered a helpful marker of overlap syndrome. However, the presence of SLA in PBC patients does appear to correlate with overlap with AIH. ${ }^{72}$

On a practical note, what does the surgical pathologist need to know about AIH-PBC overlap syndrome? Exact classification of these patients may change as we learn more about the pathophysiology of these diseases. The term 'overlap syndrome' should not be overused by applying it to otherwise typical cases of PBC with prominent interface hepatitis. In general, in low-titer AMA-positive patients, if the liver biopsy shows features typical of AIH, such as prominent piecemeal necrosis, numerous plasma cells in the inflammatory infiltrate, and lobular hepatitis, without prominent bile duct destruction, and liver tests favor a hepatitic process over chronic cholestasis, clinicians will often consider this patient to have $\mathrm{AIH}$ and prescribe immunosuppressive therapy such as corticosteroids. As UDCA has few side effects, it may be used as well. True overlap syndromes do occur but are fairly rare, constituting less than $10 \%$ of PBC patients, ${ }^{73}$ and most patients with clinical or histologic features that strongly suggest a component of AIH will be treated with a course of immunosuppression.

\section{AIH-PSC Overlap}

AIH-PSC overlap is not uncommon in young patients with autoimmune liver disease ${ }^{74,75}$ and may comprise $6 \%$ of patients with $\mathrm{AIH}^{56}$ and $8 \%$ of PSC patients (Figure 21). ${ }^{76}$ In one 16-year prospective study ${ }^{16}$ in which 55 children with AIH were followed, 27 developed cholangiographic findings typical of PSC. The term 'autoimmune sclerosing cholangitis' (ASC) has been proposed for this AIHPSC overlap syndrome. In comparison to patients with AIH, IBD is more common in the patients with ASC, and these patients are more commonly pANCA positive. In general, patients with AIHPSC overlap are younger at presentation than classic PSC patients, and may have improved survival. ${ }^{77}$ Treatment is with UDCA, combined with immunosuppression. It is also important to note that $\mathrm{AIH}$ 


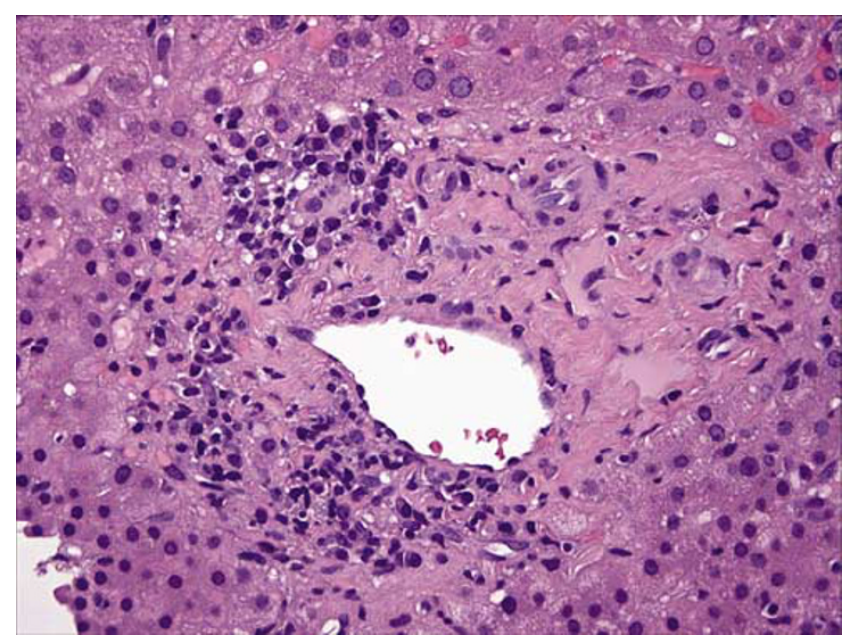

Figure 21 PSC-AIH overlap syndrome. Bile duct injury and loss with prominent plasma cells and focal interface hepatitis.

and PSC can occur sequentially (Table 6); this pattern was first described in children, ${ }^{16}$ but may also be seen in adults. ${ }^{78}$

The diagnosis of PSC and/or AIH can be particularly problematic in pediatric patients, so a high index of suspicion on the part of the gastroenterologist and the pathologist is often necessary to make the diagnosis of PSC in this setting. Although alkaline phosphatase is usually elevated in adults with PSC, normal alkaline phosphatase levels may be seen in children with the disease; in one study of 32 children with PSC, 15 had normal alkaline phosphatase levels at presentation. ${ }^{75}$ Most pediatric patients with PSC will also have ulcerative colitis (55\%), although this figure is less than the commonly quoted $70 \%$ association in adults. The cholangiogram may show very subtle irregularities of bile ducts, without overt stricture formation, and predominance of intrahepatic disease is common in childhood PSC. Concentric periductal fibrosis is rarely seen in biopsies from children; instead, the most notable feature is the loss of interlobular bile ducts, which often seem to vanish without a trace. The portal tracts may contain a dense mononuclear inflammatory infiltrate, with piecemeal necrosis and scattered plasma cells, further resembling AIH. It has been suggested that AIH and sclerosing cholangitis are similar in prevalence in pediatric patients and may represent different ends of a spectrum of autoimmune disease in this population. ${ }^{16}$

Evidence for a PSC-PBC overlap syndrome is limited and based upon case reports. ${ }^{79}$

\section{Role of liver biopsy in autoimmune liver disease}

The liver biopsy is an essential element in diagnosis and management of AIH. As individual histologic, serologic, and clinical features are not specific for the diagnosis of AIH, evaluation of the liver biopsy serves to help exclude other potential causes of liver disease and identify variant syndromes. ${ }^{80}$ Assessment of necroinflammatory activity (grade) is also important, particularly if withdrawal of immunosuppressive therapy is contemplated. For PBC, examination of the liver biopsy, in addition to providing confirmatory evidence for diagnosis, serves to determine stage of disease. Although it is recognized that disease severity is variable within the liver, evaluation of extent of fibrosis often provides helpful information regarding prognosis and may serve to guide therapy. In PSC, whereas the biopsy may not be diagnostic and may show only nonspecific changes, staging information may be clinically useful.

\section{References}

1 Boberg KM. Prevalence and epidemiology of autoimmune hepatitis. Clin Liver Dis 2002;6:347-359.

2 Toda G, Zeniya M, Watanabe F, et al. Present status of autoimmune hepatitis in Japan-correlating the characteristics with international criteria in an area with a high rate of HCV infection. J Hepatol 1997;26:12071212.

3 McFarlane IG. Autoimmune hepatitis: diagnostic criteria, subclassifications, and clinical features. Clin Liver Dis 2002;6:317-333.

4 Alvarez F, Berg PA, Bianchi FB, et al. International Autoimmune Hepatitis Group Report: review of criteria for diagnosis of autoimmune hepatitis. J Hepatol 1999;31:929-938.

5 Johnson PJ, McFarlane IG. Meeting report: International Autoimmune Hepatitis Group. Hepatology 1993; 18:998-1005.

6 Czaja AJ, Cassani F, Cataleta M, et al. Antinuclear antibodies and patterns of nuclear immunofluorescence in type 1 autoimmune hepatitis. Digest Dis Sci 1997;42:1688-1696.

7 Gorelik M, Debski R, Frangoul H. Autoimmune hemolytic anemia with giant cell hepatitis: case report and review of the literature. [Review] [22 refs]. J Pediatr Hematol/Oncol 2004;26:837-839.

8 Verma S, Guuwan B, Mendler M, et al. Factors predicting relapse and poor outcome in type I autoimmune hepatitis: role of cirrhosis development, patterns of transaminases during remission and plasma cell activity in the liver biopsy. Am J Gastroenterol 2004;99:1510-1516.

9 Czaja AJ, Carpenter HA. Histological features associated with relapse after corticosteroid withdrawal in type 1 autoimmune hepatitis. Liver Int 2003;23:116-123.

10 Singh R, Nair S, Farr G, et al. Acute autoimmune hepatitis presenting with centrizonal liver disease: case report and review of the literature. Am J Gastroenterol 2002;97:2670-2673.

11 Pratt DS, Frwaz KA, Rabson A, et al. A novel histological lesion in glucocorticoid-responsive chronic hepatitis. Gastroenterology 1997;113:664-668.

12 Abraham SC, Burgart LJ. Isolated centrilobular hepatitis: a distinctive histologic lesion with several clinicopathologic associations. Mod Pathol 2004; 17S1:294A. 
13 Czaja AJ, Carpenter HA. Autoimmune hepatitis with incidental features of bile duct injury. Hepatology 2001;34:659-665.

14 Bach N, Thung SN, Schaffner F. The histological features of chronic hepatitis $\mathrm{C}$ and autoimmune chronic hepatitis: a comparative analysis. Hepatology 1992;15:572-577.

15 Zen Y, Harada K, Sasaki M, et al. Are bile duct lesions of primary biliary cirrhosis distinguishable from those of autoimmune hepatitis? Interobserver histological agreement on trimmed bile ducts. J Gastroenterol 2005;40:164-170.

16 Gregorio GV, Portmann B, Karani J, et al. Autoimmune hepatitis/sclerosing cholangitis overlap syndrome in childhood: a 16-year prospective study. Hepatology 2001;33:544-553.

17 Marceau G, Lapierre P, Beland K, et al. LKM1 autoantibodies in chronic hepatitis $\mathrm{C}$ infection: a case of molecular mimicry? Hepatology 2005;42:675-682.

18 Selmi C, Invernizzi P, Keefe EB, et al. Epidemiology and pathogenesis of primary biliary cirrhosis. J Clin Gastroenterol 2004;38:264-271.

19 Prince M, Chetwynd A, Newman W, et al. Survival and symptom progression in a geographically based cohort of patients with primary biliary cirrhosis: follow-up for up to 28 years. Gastroenterology 2002;123:1044-1051.

20 Leuschner M, Dietrich CF, You T, et al. Characterisation of patients with primary biliary cirrhosis responding to long term ursodeoxycholic acid treatment. Gut 2000;46:121-126

21 Corpechot C, Carrat F, Bahr A, et al. The effect of ursodeoxycholic acid therapy on the natural course of primary biliary cirrhosis. Gastroenterology 2005;128: 297-303.

22 Khettry U, Anand N, Faul PN, et al. Liver transplantation for primary biliary cirrhosis: a long-term pathologic study. Liver Transplant 2003;9:87-96.

23 Migliaccio C, Van De Water J, Ansari AA, et al. Heterogeneous response of antimitochondrial antibodies to pyruvate dehydrogenase complex E2: the molecule versus the mimic. Hepatology 2001;33: 792-801.

24 Kaplan M, Gershwin M. Primary biliary cirrhosis. N Engl J Med 2005;353:1261-1273.

25 Kita H, Naidenko O, Kronenberg M, et al. Quantitation and phenotypic analysis of natural killer $\mathrm{T}$ cells in primary biliary cirrhosis using a human CD1d tetramer. Gastroenterology 2002;123:1031-1043.

26 Itoh S, Ichida $\mathrm{T}$, Yoshida $\mathrm{T}$, et al. Autoantibodies against a $210 \mathrm{kDa}$ glycoprotein of the nuclear pore complex as a prognostic marker in patients with primary biliary cirrhosis. J Gastroenterol Hepatol 1998; 13:257-265.

27 Weisner RH, LaRusso NF, Ludwig J, et al. Comparison of the clinicopathologic features of primary sclerosing cholangitis and primary biliary cirrhosis. Gastroenterology 1985;88:108-114.

28 Saxena R, Hytiroglou P, Thung SN, et al. Destruction of canals of Hering in primary biliary cirrhosis. Hum Pathol 2002;33:983-988.

29 Marucci L, Ugili L, Macarri G, et al. Primary biliary cirrhosis: modalities of injury and death in biliary epithelium. Digest Liver Dis 2001;33:576-583.

30 Yamamoto K, Terada R, Okamoto R, et al. A scoring system for primary biliary cirrhosis and its application for variant forms of autoimmune liver disease [see comment]. J Gastroenterol 2003;38:52-59.
31 Rubio CA. Qualitative and quantitative differences between bile ducts in chronic hepatitis and in primary biliary cirrhosis. J Clin Pathol 2000;53:765-769.

32 Devaney K, Goodman ZD, Epstein MS, et al. Hepatic sarcoidosis: clinicopathologic features in 100 patients. Am J Surg Pathol 1993;17:1272-1280.

33 Alam I, Levenson SD, Ferrell LD, et al. Diffuse intrahepatic biliary strictures in sarcoidosis resembling sclerosing cholangitis. Digest Dis Sci 1997;42: 1295-1301.

34 Scheuer PJ. Primary biliary cirrhosis. Proc R Soc Med 1967;60:1257-1260.

35 Ludwig J, Dickson ER, McDonald GS. Staging of chronic non-suppurative cholangitis (syndrome of primary biliary cirrhosis). Virchows Arch (A) 1978; 379:103-112.

36 Feld JJ, Heathcote EJ. Epidemiology of autoimmune liver disease. J Gastroenterol Hepatol 2003;18:11181128.

37 Lindberg BU, Broome U, Perrson B. Proximal colorectal dysplasia or cancer in ulcerative colitis. The impact of primary sclerosing cholangitis and sulfasalazine: results from a 20-year surveillance study. Dis Colon Rectum 2001;44:77-85.

38 Bergquist A, Ekbom A, Olsson R, et al. Hepatic and extrahepatic malignancies in primary sclerosing cholangitis. [see comment]. J Hepatol 2002;36:321-327.

39 Boberg KM, Spurkland A, Rocca G, et al. The HLADR3, DQ2 heterozygous genotype is associated with an accelerated progression of primary sclerosing cholangitis. Scand J Gastroenterol 2001;36:886-890.

40 Broome U, Olsson R, Loof L, et al. Natural history and prognostic factors in 305 Swedish patients with primary sclerosing cholangitis. Gut 1996;38:610-615.

41 Angulo T, Larson DR, Therneau TM, et al. Time course of histological progression in primary sclerosing cholangitis. Am J Gastroenterol 1999;94:3310-3313.

42 Burak KW, Angulo P, Lindor KD. Is there a role for liver biopsy in primary sclerosing cholangitis? Am J Gastroenterol 2003;98:1155-1158.

43 Nikolaidis NL, Guouleme OI, Tziomalos KA, et al. Small-duct primary sclerosing cholangitis: a single center sever-year experience. Digest Dis Sci 2005;50: 324-326.

44 Angulo P, Maor-Kendler Y, Lindor KD. Small-duct primary sclerosing cholangitis: a long-term follow-up study. Hepatology 2002;35:1494-1500.

45 Casali AM, Carbone G, Cavalli G. Intrahepatic bile duct loss in primary sclerosing cholangitis: a quantitative study. Histopathology 1998;32:449-453.

46 Ludwig J, Colina F, Poterucha JJ. Granulomas in primary sclerosing cholangitis. Liver 1995;15:307-312.

47 Katabi N, Albores-Saavedra J. The extrahepatic bile duct lesions in end-stage primary sclerosing cholangitis. Am J Surg Pathol 2003;27:349-355.

48 Ferrell L. Malignant liver tumors that mimic benign lesions: analysis of five distinct lesions. Semin Diagn Pathol 1995;12:64-76.

49 Carpenter HA. Bacterial and parasitic cholangitis. Mayo Clin Proc 1998;73:473-478.

50 Ludwig J, Kim $\mathrm{CH}$, Wiesner $\mathrm{RH}$, et al. Floxuridininduced sclerosing cholangitis: an ischemic cholangiopathy? Hepatology 1989;9:215-218.

51 Phongkitkarun S, Kobayashi S, Varavithya V, et al. Bile duct complications of hepatic arterial infusion chemotherapy evaluated by helical CT. Clin Radiol 2005;60:700-709. 
52 Kaplan KJ, Goodman ZD, Ishak KG. Liver involvement in Langerhans' cell histiocytosis: a study of nine cases. Mod Pathol 1999;12:370-378.

53 Debray D, Pariente D, Urvoas E, et al. Sclerosing cholangitis in children. J Pediatr 1994;124:49-56.

54 Chazouilleres O, Wendum D, Serfaty L, et al. Primary biliary cirrhosis-autoimmune hepatitis overlap syndrome: clinical features and response to therapy. Hepatology 1998;28:296-301.

55 Lohse AW, zum Buschenfeld KH, Franz B, et al. Characterization of the overlap syndrome of primary biliary cirrhosis (PBC) and autoimmune hepatitis: evidence for it being a hepatitic form of PBC in genetically susceptible individuals. Hepatology 1999;29:1078-1084.

56 Czaja AJ. The variant forms of autoimmune hepatitis. Ann Intern Med 1996;125:588-598.

57 Miyakawa H, Tanaka A, Kikuchi K, et al. Detection of antimitochondrial autoantibodies in immunofluorescent AMA-negative patients with primary biliary cirrhosis using recombinant autoantigens. Hepatology 2001;34:243-248.

58 Goodman ZD, McNally PR, Davis DR, et al. Autoimmune cholangitis: a variant of primary biliary cirrhosis. Clinicopathologic and serologic correlations in 200 cases. Digest Dis Sci 1995;40:1232-1242.

59 Invernizzi P, Crosignani A, Battezzati PM, et al. Comparison of the clinical features and clinical course of antimitochondrial antibody-positive and -negative primary biliary cirrhosis. Hepatology 1997;25:1090-1095.

60 Lacerda MA, Ludwig J, Dickson ER, et al. Antimitochondrial antibody-negative primary biliary cirrhosis. Am J Gastroenterol 1995;90:247-249.

61 Michieletti P, Wanless IR, Katz A, et al. Antimitochondrial antibody negative primary biliary cirrhosis: a distinct syndrome of autoimmune cholangitis. Gut 1994;35:260-265.

62 Taylor SL, Dean PJ, Riely CA. Primary autoimmune cholangitis: an alternative to antimitochondrial antibody-negative primary biliary cirrhosis. Am J Surg Pathol 1994;18:91-99.

63 Czaja AJ, Carpenter HA, Santrach PJ, et al. Autoimmune cholangitis within the spectrum of autoimmune liver disease. Hepatology 2000;31:1231-1238.

64 Comay D, Cauch-Dudek K, Hemphill D, et al. Are antibodies to carbonic anhydrase II specific for antimitochondrial antibody-negative primary biliary cirrhosis? Digest Dis Sci 2000;45:2018-2021.

65 Gordon SC, Quattrociocchi-Longe TM, Khan BA, et al. Antibodies to carbonic anhydrase in patients with immune cholangiopathies. [see comment]. Gastroenterology 1995;108:1802-1809.

66 O’Donohue J, Wong T, Portmann B, et al. Immunohistochemical differences in the portal tract and acinar infiltrates between primary biliary cirrhosis and autoimmune cholangitis. Eur J Gastroenterol Hepatol 2002;14:1143-1150.
$67 \mathrm{Li} \mathrm{CP,} \mathrm{Tong} \mathrm{MJ,} \mathrm{Hwang} \mathrm{SJ,} \mathrm{et} \mathrm{al.} \mathrm{Autoimmune}$ cholangitis with features of autoimmune hepatitis: successful treatment with immunosuppressive agents and ursodeoxycholic acid [see comment]. J Gastroenterol Hepatol 2000;15:95-98.

68 Terracciano LM, Patzina RA, Lehmann FS, et al. A spectrum of histopathologic findings in autoimmune liver disease. Am J Clin Pathol 2000;114:705-711.

69 Angulo P, El-Amin O, Carpenter HA, et al. Development of autoimmune hepatitis in the setting of longstanding primary biliary cirrhosis. Am J Gastroenterol 2001;3021-3027.

70 Guebel AP, Baggenstoss AH, Summerskill WH. Responses to treatment can differentiate chronic active liver disease with cholangitic features from primary biliary cirrhosis syndrome. Gastroenterology 1976;71: 444-449.

71 Joshi S, Cauch-Dudek K, Wanless IR, et al. Primary biliary cirrhosis with additional features of autoimmune hepatitis: response to therapy with ursodeoxycholic acid [see comment]. Hepatology 2002;35: 409-413.

72 Kanzler S, Bozkurt S, Herkel J, et al. Presence of SLA/ LP autoantibodies in patients with primary biliary cirrhosis as a marker for secondary autoimmune hepatitis (overlap syndrome). Dtsch Med Wochenschr 2001;126:450-456.

73 Beuers U. Hepatic overlap syndromes. J Hepatol 2005;42:S93-S99.

74 Kaya M, Angulo P, Lindor KD. Overlap of autoimmune hepatitis and primary sclerosing cholangitis: an evaluation of a modified scoring system [see comment]. J Hepatol 2000;33:537-542.

75 Wilschanski $\mathrm{M}$, Chait $\mathrm{P}$, Wade JA, et al. Primary sclerosing cholangitis in 32 children: clinical, laboratory, and radiographic features, with survival analysis. Hepatology 1995;22:1415-1422.

76 van Buuren HR, van Hoogstraten HJE, Terkivatan T, et al. High prevalence of autoimmune hepatitis among patients with primary sclerosing cholangitis. J Hepatol 2000;33:543-548.

77 Floreani A, Rizzotto ER, Ferrara F, et al. Clinical course and outcome of autoimmune hepatitis/primary sclerosing cholangitis overlap syndrome. Am J Gastroenterol 2005;100:1516-1522.

78 Abdo AA, Bain VG, Kichian K, et al. Evolution of autoimmune hepatitis to primary sclerosing cholangitis: a sequential syndrome [see comment]. Hepatology 2002;36:1393-1399.

79 Burak KW, Urbanski SJ, Swain MG. A case of coexisting primary biliary cirrhosis and primary sclerosing cholangitis: a new overlap of autoimmune liver diseases. Digest Dis Sci 2001;46:2043-2047.

80 Carpenter HA, Czaja AJ. The role of histologic evaluation in the diagnosis and management of autoimmune hepatitis and its variants. Clin Liver Dis 2002;6: 397-417. 